\title{
Musical Culture of Nakhchivan in the Turkic World
}

\author{
Gulieva Aynura \\ Head of the Department of Folks' Musical Instruments \\ Nakhchivan State University, Nakhchivan, Azerbaijan Republic \\ E-mail: hb@karvan.net
}

Received: February 23, $2011 \quad$ Accepted: April 8, $2011 \quad$ doi:10.5539/ass.v7n5p244

\begin{abstract}
Our subject of studying was a special status regional Nakhchivan folklore dance of Yalli on the background of the Turkic folklore dance with the same name, which performing particularly in eastern Turkey. Studying in detail the music in both regions accompanied the ancient form of dance as well. Musical culture of the Nakhchivan Autonomous Republic, located on the eastern borders of Turkey has a lot common peculiarities as a local music. Both in Turkey and in the Nakhchivan people living in both side of border has one language, common roots of which go back centuries. So for us, presented a particular interest to do a comparative analysis of both the dance and music, the answer, receiving to our problems would be shed light on issues relating to the music and dance culture of the peoples living so long without any contact with each other. The results of our studies provide an opportunity to come to the conclusion that in Nakhchivan and Turkish music with the mutual dependence of the elements of music is similar. Hence, the structure of the music, its introduction, middle and ending is determined by the cawing modal, modal basis. In addition, in the Nakhchivan and Turkey, "Yalli" methods of ringtones are also equal.
\end{abstract}

Keywords: Nakhchivan folklore dance, Yalli, Musical culture, Turkic folklore

\section{Introduction}

Musical Culture of Azerbaijan in the regional aspect has not been sufficiently highlighted. Study of local peculiarities of the musical culture of Azerbaijani people today is one of the important subjects. In this regard, musical culture with a very ancient history of the people of Nakhchivan Autonomic Republic of Azerbaijan as a isolated at the Soviet empire policy from the whole country of Azerbaijan, as a historical and geographical location undoubtedly presents a particular interest. Study of the Nakhchivan musical culture from a prism of common Turkic music, as an inextricably part of this ancient and grandiose culture and comparative analysis of Nakhchivan and Turkish musical cultures allow us to show as a solitary characteristic of each of them, as well as a commons features encountered of both of them more clearly, conceiving in the broadest possible terms. The purpose of the study is to examine the Nakhchivan musical culture in comparison with the Turkic world. In this regard, we focus on the elements of the performance of Nakhchivan and Turkish national dances "Yalli", which finds their common expressions in the following factors:

1) In the sources of genres (roundelay, collective dance, folk-dancing);

2) In the specificity of the rhythms, and

3) In particular of the harmony bases

But along with this, we must emphasize the fact that there are unique, peculiar and specific, even differing from each other elements and features in both the melody of dance music and performing of the ancient dance, which were discovered as a result of rigorous scientific analysis.

\section{Methodology}

When comparing the Nakhchivan and Turkish Yalli emphasis should be placed on those factors that indicate in most cases, they are identity, necessary to record the presence in their typical close, even identical traits. First of all, has been proved the identity of the genre. As it is known, the genre has the following properties:

1) the type of content;

2) national specificity; 
3) the specific features of the genre;

4) typification of vital importance issues in the genre;

5) the possession of the genre a genre diversity;

6) the presence of a certain genre of contacts of the genre.

All these aspects of the properties listed above as in Nakhchivan, and in Turkish music of the Yalli are match. The development of melody of Nakhchivan and Turkish Yalli is based primarily on the development of harmony. Thanks just latters' and the harmony intonations' peculiarities in Yalli achieved the procession formation and development of the form. Both in Nakhchivan and Turkish music a performing sound plays the same role. Sounds in them are very active. This proactive ascent of the sample melodic development fully complies with the very nature of genre of Yalli. Hence one can speak about enriching the musical fabric with active style of melodic development. This is possible due to continuous and closed circular motion around a melodic line of supporting screens, resulting in a somewhat / disconnected circles, based on circular motion, and this in turn increases the intensity of the three melodic turns. Hence, we can come to this conclusion that there are different types of circular movements - from simple performing of music up to a chain of circular shapes of dance. For example, supporting types of various sounds, slow-motioned sounds, the sounds of wired and predemy detention, performing of the third and quint, introductory tone, filling in sixths, septum (sevenths). The difference in Nakhchivan Yalli is that the auxiliary sounds possess of the functional motivational richness of content value, in the sense in the aspect of the functionality of the music.

In the Turkic samples the auxiliary sounds often form a more ornamental and intonation set.

The slowed-motion sound as a manifestation of a metric variable sound prevalent in Azerbaijani music. Slowed down sound is of particular importance in tonic cadence Mugams such as "Shur" and a "Seighah".

A specific feature of Nakhchivan and Turkish Yalli as a whole is the presence of a chain of the slow-motion sounds, allowing for more expressive melodies. In this chain slow-motion sound in every way emphasizes. Repetition of sounds in Nakhchivan and Turkish Yalli creates activity, as the frequent repetition of sounds in its turn creates an active, lively and cheerful rhythm, which in turn is identical to dynamic of the harmonically repetitive movements and content of Yalli. Melody of Yalli saturated at low and high sounds and beyond rhythm sounds as well with a quart-kvintative jumps.

Much in common in Nakhchivan and Turkish Yalli found in the area of so-called "hidden intervals". A greater number of them occurs in the melody. The definition for "hidden interval" for both of the melodies is similar. Often they are the basis for the ornamental expression of melody. "Hidden intervals" in melodies perform several functions:

1) completion of intervals;

2) providing of the dynamic of the melodies;

3) enrichment of the melody in the ornamental value;

4) association with the "hidden intervals" of different regions of form - i.e. junction function.

Methods for expression of melodic line in Nakhchivan and Turkish Yalli are identical as well. In both cases, a line of melody, especially, should be observed waviness. The length of the melodic waves in Nakhchivan and Turkish music can be both big and small. Location harmony supports on the melodic waves are also similar to the manner. Thus, the pivot of harmony can be both a beginning and middle, as well as at the end of the wave.

The process of reaching a culmination moment in both types of Yalli also goes the same way. Talking about the different ways of enrichment gradually raising and lowering movements of melodic line, we should note the graduation of it.

Ornamentation in the performance of circular motions of a dance as in Nakhchivan, and in Turkish music is also achieved by combining the short motifs in "grupett" and "mordents".

Wide movements in the Yalli of Turkish melodies create a certain tension and marked in the musical text quite clearly. In Nakhchivan Yalli same jump on a wide interval (a quart or quint) generally is proportional to further fill of this interval.

The highest sound which is like the climax of the spokesman of melodies in both Turkey and Nakhchivan "Yalli" is defined differently. In Nakhchivan Yalli culmination expressed more intensively and expressively in terms of harmony and accompanied by intense sound. Nakhchivan and Turkish Yalli relies on the smooth movement of melody, rising from the beginning to form a climax, then falling, and culminating in the peak of 
the climax of expressions of dance and choral groups, symbolizing the common goals of society (the result). A distinctive feature of this movement is a set of short phrases that enhance the smooth melody. However, here we must also note the distinctive features of Nakhchivan and Turkish Yalli. In Turkish Yalli, these short movements (Arazes), often follow each other and contribute to the expansion of the range and cause the modulation. In Nakhchivan Yalli is such a short movement phrases are set in a strict order and justified structurally dramatic context of the dance. In addition, in the Nakhchivan Yalli, in contrast to the Turkish band (what?) Is relatively small.

It should be noted that they have also found multicomponent Yalli in Nakhchivan. This type of Yalli is characterized with varying metrorhythm. However, they, unlike to two-componental Yalli not so many. In Turkey, on the contrary multiple-component Yalli is characterized with variable metrorhythm majority.

\section{Summary and conclusion}

Most of the general distinguishing features of Nakhchivan and Turkish Yalli are the evidence which can let us to agree extent of free melodic form. This leads to the conclusion that in both cases, i.e. and in the Nakhchian and Turkish music with the mutual dependence of the elements of music is similar. Hence, the structure of the music, its introduction, middle and ending is determined by the cawing modal, in accordance to modal basis. In addition, in Nakhchivan and Turkey, methods of Yalli ringtones are also equal. Nakhchivan Yalli, behold the choreography, energetic nature, differ in degree. It does not allow for different races intonations, abrupt change metrorhythm and freedom modal plan. Usually, in Nakhchivan Yalli's harmony tone is constant, stable, melodic ascents and descents are at the same height as part of the form differs in their symmetry. In Turkey the same Yalli contrast, sharp harmony tone is often accompanied by variability, variability metrorhythm and wide interval movements.

Metrorhythmical content of Nakhchivan and Turkish Yalli often coincide. However, we should note that in Turkey Yalli there is a clear analysis metrorhythm unit.

As a result, we would like to note that a comparative analysis of Nakhchivan and Turkish music samples on its own is the next step of the nucleation of the theoretical foundations of the new object, called the Turkic music. The main objective of Turkic music is in a deep study of the general laws of development of musical culture of Turkic peoples and on the basis of common and almost the same historical processes as well as in finding different ways of development and distinguishing features of their forms. Thus, Nakhchivan and Turkish folk music and represent adequate and perfect in terms of its structure and content, and demonstrate their common roots, musical compositions. Comparison of these samples showed that image and category in the national music of every nation have the same parameters. In addition, the commonality in the composite process is confirmed by common method of melodic thinking of Azerbaijani and Turkish peoples. Identified in the analysis of similarities of melodic systems revealed a common origin of both cultures.

\section{References}

Alekperov, A. (1994). Round dance Yalli of Nakhchivan area. Baku, 21.

Belyaev, V. M. (1971). Turkish music. On the musical folklore and ancient literature, 233.

Hajibeyov, U. (1929). On the Azerbaijani and Turkic folk music. At the turn of the East. Baku, No. 3, 76.

Hajiyev, N. C. (1979). Turkic-speaking areas of the Caucasus. Nauka, Moscow, 225.

Hasanov, A. (1997). The relevance of studies of Turkish and Azerbaijani music links. Collection of articles, Vol. 2, 14-19.

Hasanov, A. (1998). Intonation and typological connection to the Azerbaijani and Turkish folklore. Baku, 45.

Hasanov, A. (1998). The significance values of the national culture of Turkic peoples in the development of modern Azerbaijani and Turkish culture. Science, No. 1, 3.

Hasanov, A. (1999). The issue of comparative analyze of Azeri and Turkish music. Baku, 132-136.

Hasanov, K. (1988). Ancient Azerbaijani folk dances. Baku, 130.

Saldzhy, V. L. (1940). Hidden Turkish folk music and questions of harmony in Turkish folk music. Istanbul, 56.

Shakirzade, N. (1991). Art of Communications of Azerbaijan and Turkish music. Moscow, 15. 